\title{
Literature Review Organizer
}

\author{
Dr. Charles E. Notar (Corresponding author) \\ Jacksonville State University, College of Education and Professional Studies \\ Department of Secondary Education \\ 700 Pelham Road North, Ramona Wood A3 \\ Jacksonville, Alabama 36265-1602, United States of America \\ Tel: 1-256-782-5832Ｅ-mail: cnotar@jsu.edu \\ Dr. Virginia Cole \\ Jacksonville State University, College of Education and Professional Studies \\ Department of Secondary Education \\ 700 Pelham Road North, Ramona Wood A4 \\ Jacksonville, Alabama 36265-1602, United States of America \\ Tel: 1-256-782-5853Ｅ-mail: vcole@jsu.edu
}

\begin{abstract}
The authors provide an explanation of a literature review and a form and frame of reference for organizing references for a literature review. There are several aspects of a literature review that can be streamlined with proper organization of the reference information. A review of why a literature review is needed is provide. Problems a writer of a literature review may encounter is also discussed. The form is divided into sections with questions and helpful hints on what should be included in each section.
\end{abstract}

Keywords: Integrative reviews, Literature review, Meta-analyses, Organization, Qualitative reviews, Review of literature, Review of related literature, Systematic reviews 


\section{Introduction: Purpose and Function of a Literature Review}

The literature shows that there are at least four types of literature reviews: integrative reviews (Whittemore \& Knafl, 2005; Edgemon, Wiley, Jablonski, \& Lloyd, 2006), systematic reviews (Hemingway, 2009; ScHARR, 2009), meta-analyses (Krathwohl, 1998; Frankel \& Wallen, 2009), and qualitative reviews (Gay, Mills, \& Airasian, 2006).

Whether you are writing a literature review as an entity or as a chapter in a thesis or dissertation or for a research grant, the task is daunting. Little guidance is available on how to write a literature review. (Torraco, 2005).

The two main purposes of a literature review are first to determine what has already been done that relates to your research problem. Secondly, a review, should point out research strategies and specific procedures and measuring instruments that are productive in investigating your topic (Prinstein, 2003). In addition to these generally accepted purposes of a literature review are a number of other reasons: (1) to avoid reinventing the wheel; (2) to identify the seminal works in your area; (3) to define and measure key concepts; (4) to increase your breadth and depth of knowledge of your subject area; (5) to position your project relative to others' work and identifying potential relationships; (6) to identify opposing views; and (7) to show that you can conduct research.

The literature review allows the student to better understand the research problem in terms of historical background, theoretical framework, and current research developments or trends. Literature reviews, therefore, place the results of a study in a historical perspective. Additionally, the literature review contributes both to the design of a research study and to the interpretation of its findings. It defines and delimits the research problem by assisting in conceptualizing the problem, showing which facets of the phenomenon are important, refining it, suggesting relationships among variables, and if necessary, reducing it to a feasible size and scope.

New or barely researched topics usually require a review of any literature related in some essential way to the problem to provide a conceptual framework or rationale to the study. No project starts without showing that the proposed project builds upon what has already been done and contributes to the forward movement of the field in some significant manner. The related literature section builds further understanding of the problem by showing that it is solidly anchored in past work, yet moves beyond that work in important ways.

Related literature is that which is obviously relevant to the problem, such as previous research investigating the same variables or a similar question, references to the theory and the empirical testing of the theory, and studies of similar practices. It also assesses the strengths and weaknesses of previous studies; as well as develops a conceptual framework and rationale for the present study.

The purpose of the related literature review is to inform the reader about what already is known, what is not yet known, and about the problems or questions you plan to investigate. Also, you will need to make clear how your proposed study relates to, and builds upon, the existing knowledge base as represented in the literature. It is important to remember that 
unless your study explicitly builds on the work of other researchers in your area of inquiry, it is very unlikely to contribute to research knowledge.

\section{What is a Literature Review?}

A review of the literature is exactly that-a summary and synthesis of relevant literature on a research problem. It is a coherent, integrated, narrative, interpretative criticism that critiques the status of knowledge of a carefully defined topic of the selected relevant existing literature. A literature review is a coherent synthesis of literature presented as discursive prose.

A literature review has references that have been critically analyzed, the results of various studies compared and contrasted, and is organized on the basis of some similar type of characteristics of research articles. It is not a list describing or summarizing multiple pieces of literature.

The literature review must be relevant, appropriate, and useful to your research problem. References are only good if they are relevant to your research problem. It is critically important that the review includes only the most relevant articles. Normally, writers of literature reviews aim at comprehensiveness instead of selecting the best articles that bear on the topic. Quality of the references is more important than quantity. A review should encompass the most recent literature in both content and method; an outdated review hardly adds to the impression of scholarship. However, regardless of the date of publication of seminal sources, the deep thinkers who really grasp the field must be included! Dependence on some secondary sources such as other literature reviews may be appropriate, but as a scholar you will usually want to check some of the original literature yourself.

\section{Developing the literature review}

You are required to use a process of synthesizing and reporting the information that your literature search has revealed. (Mertler \& Charles, 2005). You must critically analyze the literature you are using as references. The review should follow through a set of concepts and questions, comparing items to each other and discussing strengths and weaknesses. It should be a concise, critical review of the nature, strengths, and limitations of other investigations. It should focus upon studies carefully selected for their relatedness to the proposed problem. Then, in summary, the literature review should make clear to the reader the extent to which prior research has succeeded in or fallen short of resolving the problem. The summary is like a summation to a jury. You want the jury to bring in the verdict you want (a preferred verdict) and you must give them in a nut shell the facts that will lead them to your verdict. The summation of the review of literature brings the reader to the point of accepting your research hypothesis as one that should be pursued.

The most common approach to a review of the literature is to group the studies that investigate similar topics or subtopics. Begin with the general information, older studies and end with the most specific, recent studies and as you analyze each study, you should look for relationships among ideas and group them as subtopics. 
It is usually unacceptable to see every paragraph beginning with the name of a researcher. You should organize the literature review so that it presents themes or identify trends, including relevant theory. You are trying to list material published that you have synthesized and evaluated according to your problem statement (thesis or research question). Remember a review of the literature should not be a loose collection of citations and miscellaneous facts that show coverage but little understanding. You must actively think about, argue with, praise, and otherwise react to your reading. Those studies closely related to the problem should include, in the review, a summary of the study, an analysis of the study, and a statement of how the study relates to the research problem. Use an overall introduction and conclusion to state the scope of your coverage and to formulate the question, problem, or concept that your chosen material illuminates.

To further refine the literature review, grouping items into sections can help you indicate comparisons and relationships. Write topic sentences that introduce the focus of each section. Group your references within the categories you have identified in your research problem. Identify the major themes - these can be used as draft major headings. (Neill, 2003). When reviewing literature, you should also code the studies as you read them. A lengthy review requires structuring with major and minor headings and periodic summaries. (McMillan \& Schumacher, 2010)

Code the studies as generally related to the research problem. Another group that could be coded are those with similar results. They should be grouped and their findings summarized as such. Show how this study fits with and "stands on the shoulders" of previous work. You can also code the reviews according to (a) variables, (b) treatments, (c) research designs and methods, (d) different results from investigations of the same problem, or (e) any combination of these.

A literature review is not judged by its length or by the number of references it includes. Rather, it is judged in the context of the proposal or the completed study. The problem, the significance of the study, and the research problem all influence the type of literature review. (McMillan \& Schumacher, 2010). Finally, remember when writing a review to ask two questions: Is what I am including relevant and supportive of the problem,” and “Am I being critical about the reference?”

\section{Problems Faced When Writing a Literature Review}

You are expected to review literature related to the problem of your study in order to accomplish three things: (a) determine whether studies already exist similar to the one you propose to do, (b) possibly obtain guidance for the investigation of your topic, and (c) establish a point of departure or a platform on which to build your research (Mertler \& Charles, 2005).

There are a number of mistakes commonly made in reviewing literature that both the novice and the professional can make: 
1. You read and do no note taking and writing. Writing helps you to understand and find relationships between the reference you are reading and your problem. (Language Center Asian Institute of Technology, (n.d))

2. You do not keep bibliographic information. Always keep bibliographic information in your notes. You will be required to have a reference section. (Language Center Asian Institute of Technology, n. d.)

3. You do not clearly relate the findings of the literature review to the researcher's own study. (Muirhead, 2004; Blum \& Muirhead, 2008; Randolph, 2009)

4. You do not take sufficient time to define the best descriptors and identify the best sources to use when reviewing literature related to one’s topic. (Randolph 2009; Muirhead, 2004)

5. You rely on secondary sources rather than on primary sources in reviewing the literature. (Blum \& Muirhead, 2005; Randolph, 2009)

6. You uncritically accept another researcher's findings and interpretations as valid. You should examine critically all aspects of the research design and analysis. (Randolph 2009; Muirhead, 2004)

7. You as the author do not report the search procedures that were used in the literature review. (Muirhead, 2004; Blum \& Muirhead, 2005; Randolph, 2009)

8. You use reference reports as isolated statistical results rather than synthesizing them by chi-square or meta-analytic methods. (Randolph, 2009; Fink, 2009)

9. Your literature review does not consider contrary findings and alternative interpretations in synthesizing qualitative data/literature. (Fink, 2009; Bloomberg \& Volpe, 2008)

One should examine the factors that discourage writers in higher education, including being affected by distractions and lack of time, writing blocks stemming from early experience, writing with grandiosity and perfectionism, writing anxiety, and establishing and maintaining momentum; and dealing with exclusionary policies in the editorial process. (Boice \& Jones, 1984).

University faculty have identified the main reason for poor literature reviews as poor organization of the material. (Swales \& Lindemann, 2002). Keys to effectively writing a literature are (a) systematically coding information from selected studies, (b) developing common measures to describe outcomes in the selected studies, and (c) evaluating research quality (Froese, Gantz, \& Henry, 1998). There is a need for methodological strategies specific to the integrative review method to enhance the rigor of the process (Whittemore \& Knafl, 2005).

\section{The Related Research Report Form}

The Related Research Report Form has been constructed to help you overcome the problems of poor organization cited by university faculty. Related Research Report Form has eight sections. The sections are laid out in a logical order for use in organizing a literature review. 
The sections are: Source, Group/Heading, Problem/Scope, Methods/Procedures, Analysis/Findings, Conclusion(s)/Results/Discussion of Reports, Relatedness to Researcher's Problem, Integration, and Usefulness. The Source is where you write the reference section entry of the reference. The Group Heading is where you determine the topic headings that you will use to sort the various references you will use in the literature review. The review is a factual report giving the author(s) full credit for their research. The next four parts, Problem/Scope, Methods/Procedures, Analysis/Findings, Conclusion(s)/Results/Discussion of Reports, of the form are paraphrased from THE article. [NOTE: When reading various sources you will see an interchangeability of terms for a section and that is why the Related Research Report Form has several of the names you will see for the same section.] The other sections "Relatedness to Researcher's Problem", Usefulness, and Integration" is where you, the researcher, provide your educated opinion.

Figure 1. Literature Review Organizer

Source:

APA page:

Heading:

Problem/Scope:

Methods/Procedures:

Findings//Analysis/Findings//Results and Discussion:

Conclusion(s)//Results//Results/Discussion//Conclusions, Implications, Recommendations// Summary and Conclusions:

Relatedness/Significance to Researcher's Problem:

Integration to Researcher's Problem:

Usefulness to Researcher's Problem:

Figure 1. Literature Review Organizer should be used for each source reviewed for incorporation into a review of related literature.

Source: While this section is first on the Research Report Form, it should be filled in last. You should ensure that all the parts of the related form can be completed prior to completing this section. Write the source in APA style exactly as it would be done in the reference section of your research paper. The rationale behind writing the citation in APA style is that you will not have to go back and find information for the citation later if it is not done correctly. In addition, if forms are arranged alphabetically by first author's last name, the reference section will be completed._NOTE: To help you relocate the citation "APA page" has been added to the source for you to put page and number in APA publication manual where you found citation format. DO NOT copy this part when copying and pasting the source to the reference section.) 
Group/Heading: As you read the references, you will start to see a pattern. These patterns will help you organize the review. Most journal articles require headings, assign a heading to each article, place the heading here, and then if you find other articles that are similar use that same heading or determine another heading. Once you have "completed" reading all of your references, you can organize the articles according to the heading. Then, use a one, two, or three with the heading, to determine the least to most important presentation order within the heading.

The review should flow in such a way that the least relevant references to the problem are discussed first and the most relevant are discussed last. The idea is to organize and present your literature in such a way that it leads logically to a tentative, testable conclusion, namely your hypothesis.

\section{Problem/Scope: $\quad$ Problem/Scope, Methods/Procedures, Analysis/Findings,} Conclusion(s)/Results/Discussion of Reports are where you pare down the article into a presentation of THE article. You do this through paraphrasing, giving full credit to the value of the article. If the article is in the least category then these sections will not be as robust as those that are most important. Remember the research paper is written in third person so fill the Related Literature form out in third person. The review should not contain long quotations or use the same wording in discussing different studies.

Any source has a reason for being written. That reason is provided as the research problem. The problem is in the opening of the article. It may not be labeled as such because it is in the introduction the article. If you can not find the problem in the first couple of paragraphs or by the end of the first page, this article is not needed in your review of literature, and you should stop reading and find another article. The author's problem statement helps you determine how related the article is to your research. The corresponding arguments and data summarizing should give you an idea of relatedness and a sense of confidence that the author(s) knew what they were doing and why. If the article is unrelated, stop reading and find another article. Another reason for finding the problem statement is that article titles can give the impression that the article is related, but you will find that in some cases, this is not true.

Some key identifiers for the problem or scope of the research will include the incorporation of the statement of the problem or purpose of the study. The problem should be researchable. Therefore, it should be defined and clarified. You also want to make sure that the focus of the problem is the same as yours. The background information on the development and history of the problem should be available. A source should also reveal critical questions to answer for the reader including a discussion of the educational significance of the problem. The problem statement should indicate the variables of interest and the specific relationship between those variables which were investigated. The variables should be clearly defined, and the measure of each variable should be consistent with how the variable was defined. A source should define the variables either directly or indirectly, when necessary.

Further analysis of the problem or scope of a study should allow you to pinpoint a comprehensive or selective statement of the scope of the problem. Determine if the article 
uses the same operational definitions as your problem and how the article relates to previous work in the area.

Finally, survey of a source of reference should include thought analysis of how the article relates to previous work-in the area and how the problem derived. Focus on the research problem, procedures, or findings should also help identify any unduly influence by the author(s)' institutional affiliation, beliefs, values, or theoretical orientation. You would also want to determine if the author(s) expressed a positive or negative bias in describing the subject of the study (an instructional method, program, curriculum, person, etc.). The hypotheses, questions, or objectives should be explicitly stated, and if so, should be clear? Moreover, decide whether the author(s) make a convincing case that the research hypothesis, question, or objective was important to the study.

Methods/Procedures: This section is very important for two reasons. First, if someone wants to replicate the research, there needs to be sufficient information for the reader to determine if they need to read the whole article and the supporting study. Second, this area is where you may find methods and procedures that you may want to use in your study.

From whom did the authors collect data and how did they collect the data? What research method was used? How did the author collect information to write the article? Most articles are qualitative research, reporting what the authors have observed. Remember that methods/procedures and analysis are different. Methods/procedures describe in detail how the study was conducted. Description enables the reader to evaluate the appropriateness of research method and reliability and validity of the authors' results. A key question might be "Is there enough detail provided so that the reader can replicate the author's study?"

Methods/Procedures frame of reference critical review questions

Critical review questions should focus on the methods used to complete the study, in such a manner that the procedures are replicable. The research method should be stated within the methodology section. You should determine how the hypothesis and experimental design relate to the problem. Sources should be provided through personal observations or from published literature.

The subjects of the study should be identified with a description of demographics, number of participants, and size of the target population. More specifically, the sample size should be provided and validated for statistical treatment and generalizations. In other words, you'd want to determine if the participant information is the same as yours in terms of geographic locations, grade structure, subject matter, etc. Is there a description of the materials used in the collection of data?

An appropriate methods section analysis should focus on the collection instruments used to collect data. A determination should be made on whether the collection instruments are professionally made or nationally accepted, and also, if the instruments were used correctly. A description of the procedures (steps in the experiment) should be obvious. Each measure in the study should be sufficiently valid for its intended purpose. Furthermore, each measure in 
the study should be sufficiently reliable for its intended purpose. Finally, you want to determine if each measure is appropriate for the sample.

(Quantitative) Did the sampling procedures produce a sample that is representative of an identifiable population or of your local population?

(Quantitative) Did the researchers form subgroups that would increase understanding of the phenomena being studied?

(Qualitative) Did the sampling procedures result in a case or cases that were particularly interesting and from whom much could be learned about the phenomena of interest?

A final check on the methodology utilized in a study might include a focus on if the article is based on a review of the literature, a comparison of previously published articles, or a discussion of another person's theory. In any of these scenarios, you should determine if the review is comprehensive. All of the references cited should be relevant to the problem under investigation. Most of the sources should be primary, and only a few or no secondary sources should be cited. The references should have been critically analyzed and the results of various studies compared and contrasted. More specifically, the review should be more than a series of abstracts or annotations.

You'd furthermore want to observe if the review is well organized. Does it logically flow in such a way that the references least related to the problem are discussed first and the most related references are discussed last? Finally, the review should conclude with a brief summary of the literature and its implications for the problem investigated.

Findings//Analysis/Findings//Results and Discussion: Presents the research findings. A quantitative paper will present the data collected and a statistical analysis of the data. What did the author do with the information collected? What analytical process did the author use? This leads to a summation of the findings for each of the research questions or hypotheses. A qualitative paper format may vary.

Frame of reference questions that may be used to critically review the findings, analysis, results, and discussion sections of a paper should center upon the following central ideas. A summary of the data collected and a statistical treatment should be present. Subsequently, there should be an interpretation and discussion of the implications of the data analysis. You would also want to determine if the statistical presentations are inferential or descriptive. These may be included as tables or figures, but should include statistically significance levels. Are the statistics provided sufficient, powerful, and significant?

Additional analysis of findings and results should be used to determine whether appropriate statistics were used, and whether used correctly. For qualitative studies, did the report include a "thick" description that brought to life how the individuals responded to interview questions or how they behaved? Did each variable in the study emerge in a meaningful way from the data? Finally, did clearly stated hypotheses or questions emerge from the data that were collected? 
Conclusion(s)//Results//Results/Discussion//Conclusions,Implications,Recommendations

// Summary and Conclusions: The purpose of this section is to summarize the work and present the researcher's conclusions. What are the conclusions or findings of the article? What answer(s) does the author have for the problem? Implications and limitations of the study and recommendations for further study can be presented here. Recommendations are an excellent place to find a research problem! Recommendations might include replication of the study, replication with a different population, the addition of other variables, training or screening of subjects, or a deeper analysis of a finding (Marshall University College of Education and Human Services, (n.d.)).

Critical review questions centered upon this section of a reference should focus on the author's conclusion(s) of the findings of the study. A clear statement of the support or nonsupport of the author(s)'original hypothesis should be mentioned. Similarity or difference from past research and the author's conclusions should be stated. In turn, the conclusions should be supported by the data, representative of the analysis of the data and should be direct, clear, and unambiguous. The author(s) should provide reasonable explanations of the findings, draw reasonable implications for practice from the findings, or identify any shortcomings of the study upon which the article was written?

Relatedness/Significance to Researcher's Problem: "Relatedness to Researcher's Problem, Usefulness, and Integration" is where you, the researcher, provide your educated opinion. These sections are when you are speaking. When writing in this section or elsewhere in the paper use the term "researcher/the researcher" to refer to yourself. Relatedness information is usually found in the problem and conclusion sections of an article.

Relatedness answers the question "How does this article relate to the researcher's problem?" This is where you perform a critical evaluation of the articles and explain your critical evaluation: This explanation is based on the answers to the questions posed about the specific parts of the article. Is the problem the same or close to your problem? Is the article relevant or is it tangential or of general significance? Does it identify the relationship of article to researcher's hypothesis? What contradictions, gaps, and inconsistencies, if any, in the article pertaining to research methods, tools, and tool have you identified? Is the article organized? Are the articles integrated?

You'd determine the significance of the researcher's problem through inference and how much weight the article carries. This part of the form summarizes previous investigations in order to inform the reader of the current state of research on the problem. This area is also used to suggest the next step or steps in solving the problem.

A critical review of the relatedness or significance of the problem should be based on a number of factors. When selecting literature, you want to ask if the purpose of the review (preliminary or exhaustive) indicated. The parameters of the review should be reasonable, and you want to ask the following questions: a) Why were certain bodies of literature included in the search and others excluded from it? b) Which years were included in the search? Recent developments in the problem should be emphasized in the review. The 
selected literature should be relevant to the problem, and complete bibliographic data should be provided for each reference.

To critique the literature, determine if the review is organized by topics or ideas, and not by author. Is the review organized logically? Are major studies or theories discussed in detail and minor studies with similar limitations or results discussed as a group? There should be adequate criticism of the design and methodology of important studies so that the reader can draw his or her own conclusions. The studies should be compared and contrasted, and any conflicting or inclusive results should be noted. For the purpose of clarity, the relevance of each reference to the problem should be explicit. There should not be inconsistencies in the argument and there should be no room for any of the research assumptions to be challenged.

In determining the relatedness or significance of a literature source, decide if the summary of the literature review provides an overall interpretation and understanding of our knowledge of the problem. The implications of the source should provide theoretical or empirical justification for the specific research questions or hypotheses to follow. Furthermore, the methodological implications should provide a rationale for the design to follow.

Integration to Researcher's Problem: In integration to the researcher's problem, you determine through inference, how much weight the article carries. You summarize previous investigations in order to inform the reader of the current state of research on the problem to include this article. Things to look for when reviewing articles that will help you determine if they are related to another article are relations (same population, methods, treatment of data); contradictions, gaps in the research; and inconsistencies, or any thing that will make connections between articles with your hypothesis and the literature previously reviewed. This part of the form summarizes previous investigations in order to inform the reader of the current state of research on the problem. This area is also used to suggest the next step(s) in solving the problem.

NOTE: Research reports that appear in journals usually are brief in order to meet the journals' space limitations. Their brevity and standardized format, however, make such reports less interesting to read than popular educational writing. Furthermore, you often must assume or guess about aspects of the study for which insufficient detail is provided. If important details about the study have been omitted, you can not use these references in your literature review useless you go to the original study.

If several studies have similar results, they should be grouped and their findings summarized as such. For example: Several studies found that teachers' expectations are related to student achievement (Jones, 1978; Smith, 1984; Watson, 1982).

Usefulness to Researcher's Problem: Usefulness is directed to what in the author's methods and analysis you can use in your research. Is the survey used one that you can use as is, modify? Was the statistical treatment one that you could use in your research? (Usefulness = methods and analysis)

NOTE: The form should be filled out as completely as possible. You should provide as much detail as possible. If you fill the form out completely you will not need to return to the 
original article. It is easier to delete information than to go back to find more information. There are two types of research articles: opinion (Qualitative) and data based (Empirical). It is very important that you understand that while an article may be data based the conclusions may not be supported by the data; and, therefore the article actually is a bastardized opinion article.

Identify promising ways to study the problem: Substitute shorter, less expensive time doing the literature search for lengthier, more expensive research time rediscovering what is already known, avoiding fruitless approaches, and unintentional and unnecessary replication. Determine the major variables and the relationships among variables important in the problem. Around 20-30 references for an undergraduate degree are considered the benchmark (although this will vary from institution and subject topic).

\section{Developing the Review}

The authors believe that you have to review the literature first and then construct the review. Now that we have reviewed and labeled the references for the literature review it is time to construct the literature review. There are four parts of Related Literature review: Introductory Paragraph, Review of Articles, Summary of Related Literature, and Statement of Research Hypothesis.

\section{A. Introductory Paragraph}

The introduction to the related literature section is where you tell the reader how you have organized the review: groupings - tell the reader what the groups are and their order in which they are presented. This comes from the headings you developed when reading the references and grouping them. Organize the related literature forms by heading and then by number. The headings are presented in the introductory paragraph from least important to most important. This is how they will be presented in the actual review of literature. The numbers will help you organize the article within the heading from least to most in the appropriate order.

As already stated the review is where you do the least to most important presentation of the references. Think of your presentation as an argument. When you argue you usually start with some background or history of the thing you are disputing. Then you build to the point that you believe will sway opinion to your point of view. Your argument is organized logically. So, too, is your literature review. Use topic sentences to help organize the review logically.

\section{B. Presentation of Sources Being Used in Review of Literature}

After the introductory paragraph you then present your articles based on the headings and order you have established, inserting integrated comments where appropriate.

Most research textbooks spend a great deal of time on searching for sources and types of sources. Because of this treatment elsewhere only a few comments are needed here. Use your problem statement and hypothesis key words as initial descriptors. Limit your initial search to the last ten years. Use the reference section of sources that you select to review. When you see the same author's name in several sources, look that name up for possible use in your paper. Look for seminal sources, the person(s) that came up with the original idea, theory, or 
concept. Do not forget to look at thesis, dissertations, and presentations. Be sure to look for sources on both sides of your problem. Lastly, online searching is limiting.

Before you do any reading of a reference, check for credibility of the author, if the journal is refereed, if the article is related to your problem, and contains opposing views to yours. When checking the credibility of author see if the study appears objective, are the conclusions reasonable, and was the methodology appropriate for the investigation? Check the author's prior research, is the study supported by external grants or funds, and is one of the references reporting final results of a project or an installment on the longitudinal study. Refereed or juried articles should be used and you need to know if the journal is sponsored by national organizations and does it use a blind review process. Relatedness means the reference is clearly related to the research problem or provides background or a historical perspective. You are the decision maker as to what is important to your problem from the materials on your problem. You will be judged as a researcher based on these decisions. You must present a balanced approach to the problem. Be sure to search out and report opposing views to yours.

\section{Summary of Related Literature,}

This is a summation just as if you were a lawyer in front of a jury at the end of a trial. Distill what you found in the literature.

The review should conclude with a brief summary of the literature and its implications. The length of this summary depends on the length of the review. It should be detailed enough to clearly show the logic chain you have followed in arriving at your implications and tentative conclusions. Having systematically developed and presented your rationale, you will now be ready to state your hypothesis.

Your literature review should culminate in a compelling rationale paragraph. This is where you state the "hole" in the literature that you will address, and how your study will seek to fill the "hole."

\section{Statement of Research Hypothesis}

Based on the review of literature that you have summarized declare your research hypothesis. This will be determined by the literature and you will decide if you will keep, revise, or rewrite the preliminary hypothesis as your research hypothesis.

\section{E. Finalize the Review}

Take the related Literature forms and look at the source. Put these in alphabetical order to structure your reference section. Once completed, utilize the checklist provided below.

\section{F. Literature Review Checklist}

Now that the review has been written, here is a checklist to be sure that you have met all the requirements of a literature review. A literature review is judged by three criteria: the selection of the sources, summary and analysis of the literature, and the relevance of the literature to the current study. 
Figure 2. Checklist for Selection of Literature to be Included in Literature Review

1. Is the purpose of the review (preliminary or exhaustive) indicated?

2. Are the parameters of the review reasonable? Why were certain bodies of literature included in the search and others excluded?

3. Is primary literature emphasized in the review and secondary literature, if cited, used selectively?

4. Are most of the sources from reputable, refereed journals?

5 .Are recent developments in the literature emphasized in the review?

6. Is the literature relevant to the problem?

7. Is complete bibliographic data provided for each source cited?

Summary and Analysis of Literature

1. Is the review organized by topics or ideas, not by author?

2. Is the review organized logically?

3. Are major studies discussed in detail and the actual findings cited?

4. Are minor studies with similar results or limitations summarized as a group?

5. Is there adequate analysis or critique of the methodologies of important studies so that the reader can determine the quality of previous research?

6. Are studies compared and contrasted and conflicting or inclusive results noted?

7. For some basic and applied studies and qualitative research, is the conceptual framework or theory that guides the study explained?

Relationship to Current Study

1. Does the summary provide an overall interpretation and understanding of prior research?

2. Does the review of major studies relate explicitly to the research problem and methods?

3. Do the methodological analyses provide a rationale for the design to follow?

4. Does the review of the literature help establish the significance of the research?

\section{Conclusion}

An integrated literature review is organized on the basis of some similar type of characteristics of research articles, not just article by article. The review should be comprehensive. All of the references cited should be relevant to the problem under investigation. Most of the sources should be primary with few, if any, secondary sources. The references should be critically analyzed and the results of the various studies should be 
compared and contrasted. In other words, the review should be well organized. It should flow logically in such a way that the references least related to the problem are discussed first and the most related references should be discussed last. Finally, the review should conclude with a brief summary of the literature and its implications for the problem investigated.

The Related Literature form was designed to solve problems you face when writing a review of literature. With practice using the form, you will be able to write a review of literature in a more efficient way.

\section{References}

American Psychological Association. (2001). Publication Manual of the American Psychological Association. (5 ${ }^{\text {th }}$ ed.). Washington, DC: American Psychological Association.

American Psychological Association. (2010). Publication Manual of the American Psychological Association. (6 ${ }^{\text {th }}$ ed.). Washington, DC: American Psychological Association.

Baumeister, R. F. (2003). Writing a literature review. In: The Portable Mentor: Expert Guide to a Successful Career in Psychology. Prinstein, Mitchell J. (Ed.); Patterson, Marcus D. (Ed.); New York, NY: Kluwer Academic/Plenum Publishers, 57-71. [Chapter]

Best, J. W., \& Kahn, J. V. (1993). Research in Education. ( $7^{\text {th }}$ ed.). Boston: Allyn \& Bacon.

Bloomberg, L. D., \& Volpe, M. (2008). Completing Your Qualitative Dissertation: A Roadmap From Beginning to End. Thousand Oaks, CA: SAGE Publications, Inc.

Blum, K., \& Muirhead, B. (2005). The Right Horse and Harness to Pull the Carriage: Teaching Online Doctorate Students about Literature Reviews, Qualitative, and Quantitative Methods that Drive the Problem. [Online] Available:http://www.itdl.org/Journal/Feb_05/article03.htm

Boice, R., \& Jones, F. (1984). Why academicians don't write. Journal of Higher Education, 55(5), 567-582.

Drew, C. J., Hardman, M. L., \& Hosp, J. L. (2008). Designing and Conducting Research in Education. Los Angeles, CA: SAGE Publications.

Edgemon, E. A., Wiley, A. L., Jablonski, B. R., \&. Lloyd, J. W. (2006). Conducting Integrative Reviews of Special Education Research: Overview and Case Study. Cambridge, UK: Emerald Group Publishing Limited.

Fink, A. (2009). Conducting Research Literature Reviews: What Did You Find? (3 ${ }^{\text {rd }}$ ed.). Thousand Oaks, CA: Sage Publications, Inc

Fraenkel, J. R., \& Wallen, N. E. (2003). How to design and evaluate research in education. (5 ${ }^{\text {th }}$ ed.). Boston: McGraw-Hill Higher Education.

Fraenkel, J. R., \& Wallen, N. E. (2009). How to design and evaluate research in education. ( $7^{\text {th }}$ ed.). Boston: McGraw-Hill Higher Education. 
Froese, A. D., Gantz, B. S., \& Henry, A. L. (1998). Teaching students to write literature reviews: A meta-analytic model. Teaching of Psychology, 25(2), 102-105.

Gall, M. D., Gall, J. P., \& Borg, W. R. (2003). Educational Research: An Introduction. (7 ${ }^{\text {th }}$ ed.). Boston: Pearson Education, Inc.

Galvan, J. L. (2006). Writing Literature Reviews: A guide for Student of the Social and Behavioral Sciences. ( $3^{\text {rd }}$ ed.). Glendale, CA: Pyrczak Publishing.

Gay, L. R., \& Arasian, P. (2000). Educational Research: Competencies for Analysis and Application. ( $6^{\text {th }}$ ed.). Upper Saddle River, NJ: Merrill.

Gay, L. R., Mills, G. E., \& Arasian, P. (2006). Educational research: Competencies for analysis and applications. ( $8^{\text {th }}$ ed.). Upper Saddle River, NJ: Pearson Merrill Prentice Hall.

Hemingway, P. (2009). What is a systematic review? [Online] Available: http://www.medicine.ox.ac.uk/bandolier/painres/download/whatis/Syst-review.pdf

Hendricks, C. (2006) Improving Schools Through Action Research: A Comprehensive guide for Educators. (4th ed.). Boston: Pearson Education, Inc.

Johns, A. M. (Ed.). (2002). Genre in the Classroom: Multiple Perspectives. Mahwah, NJ: Lawrence Erlbaum Associates Publishers.

Krathwohl, D. R. (1998). Methods and Social Science Research: An Integrated Approach. ( $2^{\text {nd }}$ ed.). NY: Addison Wesley Longman, Inc.

Language Center Asian Institute of Technology. (n.d.). Writing up Research Using the Literature. [Online] Available: http://www.languages.ait.ac.th/EL21LIT.HTM

Marshall University College of Education and Human Services. (n.d.). Doctor of Education. Dissertation Style Guide. [Online] Available: https://www.marshall.edu/gsepd/edd/Style_Guide.pdf

McMillan, J. H. (2004). Educational Research: Fundamentals for the Consumer. Boston: Pearson Education, Inc.

McMillan, J. H., \& Schumacher, S. (2010). Research in Education: Evidence-Based Inquiry. ( $7^{\text {th }}$ ed.). Boston, MA: Pearson.

Mertens, D. M. (2010). Research and Evluation in Education and Psychology. (3 ${ }^{\text {rd }}$ ed.).Los Angeles, CA: SAGE Publications, Inc.

Mertler, C. A., \& Charles, C. M. (2005). Introduction to Educational Research. (5 ${ }^{\text {th }}$ ed.). Boston, MA: Pearson Education, Inc.

Muirhead, B. (2004). Literature Review Advice. [Online] Available: http://www.itdl.org/journal/Feb_04/article06.htm

Neill, J. (2003). Tips for Writing an Outline (or Annotated Table of Contents). [Online] Available: 


\section{Macrothink}

International Journal of Education

ISSN 1948-5476

2010, Vol. 2, No. 2: E2

Pan, M. L. (2004). Preparing Literature Reviews: Qualitative and Quantitative Approaches. (2nd ed.). Glendale, CA: Pyrczak Publishing, Inc.

Randolph, J. J. (2009). A guide to writing the dissertation literature review. Practical Assessment, Research \& Evaluation, 14(13), 1-13.

ScHARR. (2009). Systematic reviews: What are they and why are they useful? [Online] Available: http://www.shef.ac.uk/scharr/ir/units/systrev/definitions.htm

Swales, J. M., \& Lindemann, S. (2002). Teaching the literature review to international graduate students. In: Genre in the Classroom: Multiple Perspectives. Johns, A. M. (Ed.). Mahwah, NJ: Lawrence Erlbaum Associates Publishers.

Taylor, D., \& Procter, M. (2005). The Literature Review: A Few Tips On Conducting It. Health Sciences Writing Centre, Writing Support, University of Toronto.

Thompson, G. L. (2003). Predicting African American parents' and guardians' satisfaction with teachers and public schools. Journal of Educational Research, 96(5), 277-285.

Torraco, R. J. (2005). Writing integrative literature reviews: Guidelines and examples. Human Resource Development Review, 4(3), 356-367.

University of San Francisco College of Professional Studies. (n.d.). The Graduate Research Handbook. [Online] Available: http://www.cps.usfca.edu/grh/contents.htm

Whittemore, R., \& Knafl, K. (2005). The integrative review: Updated methodology. Journal of Advanced Nursing, 52(5), 546-553. DOI: 10.1111/j.1365-2648.2005.03621.x; (AN 18724955) 